\title{
CHEMICAL PLEURODESIS USING POWDERED TETRACYCLINE TABLET FOR RECURRENT PNEUMOTHORAX
}

\author{
Prabhu M K , Mishra P*, Subish P*, Malhotra A', Sharma P*, Upadhyay D K
}

Pneumothorax, a life threatening complication in chronic obstructive pulmonary disease (COPD), requires early recognition and specific management. Recurrent pneumothorax can occur due to rupture of emphysematous bullae in COPD patients. Pneumothorax is treated by insertion of chest tube under focal drainage. Recurrent pneumothorax is treated by open thorocotomy or thorocoscopy and resection of mechanical abrasions and insufflations of talc. Non surgical methods of pleurodesis include chemical pleurodesis using talc powder $\left(\mathrm{Mg}_{3} \mathrm{Si}_{4} \mathrm{O}_{10}\left(\mathrm{OH}_{2}\right)\right)$, tetracycline, doxycycline, minocycline, bleomycin etc ${ }^{1}$. We report a case of successful pleurodesis using tablet tetracycline $(500 \mathrm{Mg})$ in a case of recurrent pneumothorax in a COPD patient.

\section{CASE REPORT}

A 70 yr old Nepali lady, chronic smoker diagnosed as of COPD with emphysematous bullae was admitted with history of sudden chest pain and severe breathlessness of two hours duration. During examination done at emergency room, patient had hypotension (BP 80/60 mm of $\mathrm{Hg}$ ), tachycardia (132 beats /Min), and hypoxia $\left(\mathrm{SaO}_{2}-80 \%\right)$ on room air with features of right sided pneumothorax.Urgent chest x-ray (Fig 1: A) revealed right sided pneumothorax (large) with small pneumothorax in left side and multiple emphysematous bullae in both lung fields. Emergency chest tube insertion was done in right side, following which, patient's oxygen saturation improved. Patient was treated with oxygen for left pneumothorax. Pneumothorax was persistent in left side even after 24 hours of oxygen therapy; intercostal drainage was done in left side also. Intercostal tubes were removed after 48 hrs of complete chest expansion with no air leak. Patient was discharged after $24 \mathrm{hrs}$ on broad spectrum antibiotics and bronchodilators.
After three days of discharge, patient was readmitted early morning with acute breathlessness for three hours duration. Clinical examination revealed features of right sided pneumothorax. Chest x-ray done showed bilateral pneumothorax, right more than left. Patient was started on oxygen, bronchodilators and put on broad spectrum antibiotics. By evening patient had features of right tension pneumothorax requiring emergency intercostal chest tube insertion on right side following which patient showed dramatic clinical improvement. Chest $x$-ray done next day showed lung expansion in right side and persistant small pneumothorax in left side.

Since patient had clinical improvement and showed reluctance towards chest tube insertion, Intercostal Chest Tube (ICD) was not done in the left side. As patient had tension pneumothorax in right side during both episodes, it was decided to do chemical pleurodesis in right side. A past history of tetracycline and lignocaine sensitivity was ruled out. After full lung expansion,

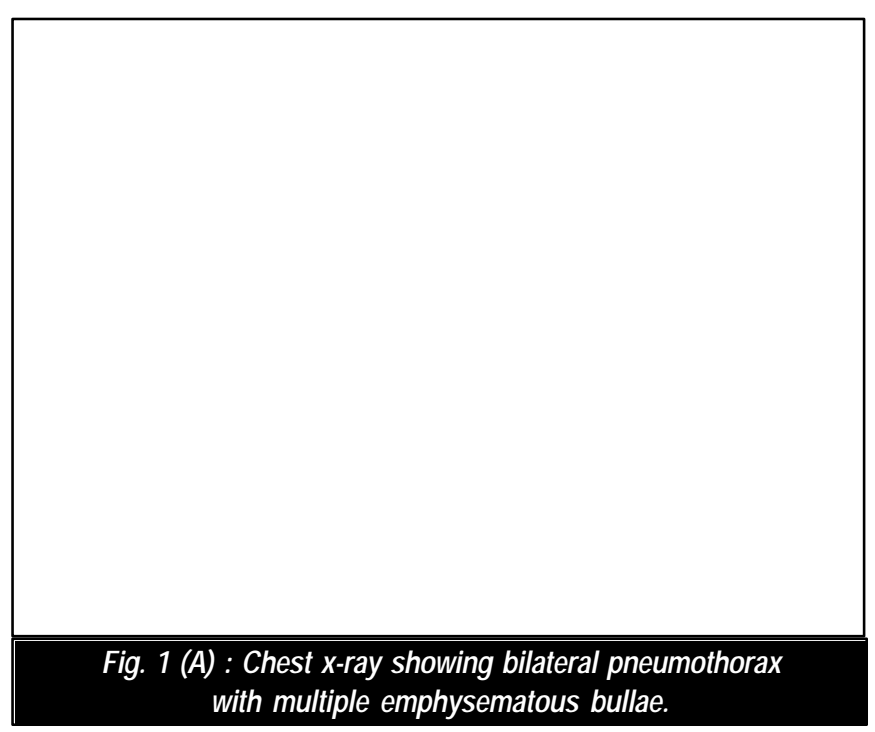

* Manipal Teaching Hospital, Pokhara, Nepal.

Address for correspondence : Dr. M. Mukhyaprana Prabhu

Manipal Teaching Hospital, Pokhara, Nepal.

Email: mmukhyaprana@yahoo.com 


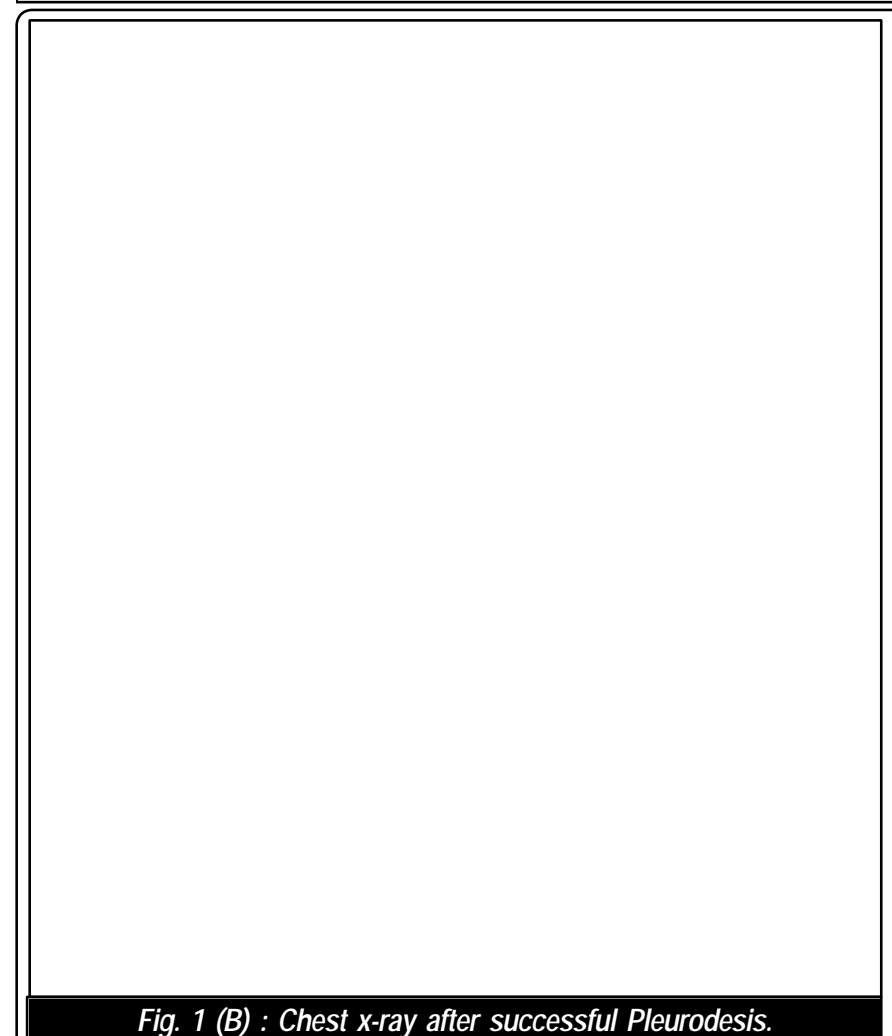

Fig. 1 (B) : Chest x-ray after successful Pleurodesis.

we used a finely powdered and well triturated form of a single $500 \mathrm{mg}$ tetracycline tablet made slurry by using approximately $5 \mathrm{ml}$ of normal saline and the final volume made to $50 \mathrm{ml}$ with normal saline. The solution was injected through ICD preceded by $2 \%$ xylocaine injection $5 \mathrm{ml}$. Patient was kept in right lateral position for distribution of tetracycline. Following the procedure, patient developed severe chest pain and tachypnea (40/Min), however oxygen saturation $\left(\mathrm{SaO}_{2}>90 \%\right)$ was maintained. The tube was clamped for 1 hour and patient was observed in Intensive Care Unit (ICU) for $24 \mathrm{hrs}$. After $24 \mathrm{hrs}$ ICD was removed and repeated chest x-ray showed full lung expansion in right side. Patient was discharged after 48 hrs and is on regular follow up (Fig 1: B). During follow up patient is asymptomatic on bronchodilator therapy. Patient was not willing for left sided chest tube and pleurodesis.

\section{DISCUSSION}

Pneumothorax is a life threatening medical emergency, if not recognized and treated early can lead to high mortality. secondary spontaneous pneumothorax is a complication of preexisting lung disease. COPD and Pneumocystis carinii pneumonia (PCP) are the most common conditions associated with secondary pneumothorax. ${ }^{2}$ Rupture of emphysematous bullae is the main cause for secondary pneumothorax in COPD patients. Recurrent pneumothorax is treated by various methods with varying degree of success rate. Video assisted thoroscopic surgery or thorocotomy with insufflations of talc has got a highest success rate of approximately $97 \%$ in preventing further recurrence. Pleurodesis by the infusion of chemical agents via a chest tube is preferable to surgery for the treatment of pneumothorax when patients are in a poor condition due to chronic pulmonary disease or some other underlying disease. ${ }^{3}$ Commonly used sclerosing agents are tetracycline, doxycycline, talc slurry, minocycline and bleomycin. Rarely coryne bacterium parvum extract, cisplatin, cytosine, arabinoside, interferons and interleukins are also used. Talc slurry pleurodesis is found to be the most effective agent of choice. ${ }^{1}$

There are studies done using tetracycline in pneumothorax for pleurodesis. ${ }^{4,5}$ How ever all these studies used parenteral tetracycline which is presently not available in many countries ${ }^{1}$ including Nepal. Since tetracycline is known to act locally through inhibition of matrix degrading metalloproteinases in pleural fluid causing pleural fibrosis and adhesion, ${ }^{6}$ we thought that powdered form of oral tetracycline tablet should be equally effective that of parenteral form in causing pleurodesis. Tetracycline pleurodesis has got a varying success rate in varying studies. The main complication pleurodesis is severe pleruritic chest pain and xylocaine is found to reduce it. ${ }^{1}$ Rare and severe complication including acute renal failure has been reported following tetracycline pleurodesis. ${ }^{7}$ In our patient, there was severe pleuritic chest pain requiring ICU observation for 24 hrs without any other complications.

Since tetracycline injection is not available in many countries and other available methods require surgical procedure and involve high cost, this economic and relatively simple alternative can be used in a resource limited settings in developing countries. However further studies involving large number of subjects is warranted in this area.

\section{REFERENCES}

1. Antunes G, Neville E, Ali $\mathrm{N}$ et al. BTS guidelines for the management of malignant pleural effusions. Thorax 2003; 58:ii29-ii38.

2. Sahn SA, Heffner JE. Spontaneous pneumothorax. NEJM 2000; 342: 868-74.

3. Kinoshita $\mathrm{T}$, Miyoshi $\mathrm{S}$, Katoh $\mathrm{M}$ et al. Intrapleural Administration of a Large Amount of Diluted Fibrin Glue for Intractable Pneumothorax. Chest 2000; 117: 790-95

4. Alfageme I, Moreno L, Vargas A et al. Spontaneous pneumothorax. Long-term results with tetracycline pleurodesis. Chest 1994; 106: 347-50.

5. Wooten SA, Barbarash RA, Strange C et al. Systemic absonption of tetracycline and lidocaine following intrapleural instillation. Chest 1988; 94: 960-63.

6 Hurewitz AN, Wu CL, Mancuso et al. Tetracycline and docycycline inhibit pleural fluid metalloproteinases. A possible mechanism for chemical pleurodesis. Chest 1993; 103: 1113-17

7. Smythe $\mathrm{WR}$, Bavaria JE. Tetracycline pleurodesis-associated acute renal failure. Chest 1993; 104: 1274-76. 